\title{
Physiological responses of the newborn infant to resuscitation
}

\author{
A. W. BOON, A. D. MILNER, AND I. E. HOPKIN \\ Department of Child Health, and Nottingham City Hospital,
}

SUMMARY Lung ventilation, endotracheal, and intraoesophageal pressures were measured during standard resuscitation of 20 asphyxiated babies born by caesarean section. The most common response to resuscitation was the production of a large positive intraoesophageal pressure. An opening pressure $>2.0 \mathrm{kPa}$ was required to expand the lungs of most of these babies. The need for resuscitation was associated with prolonged maternal anaesthesia before delivery.

Endotracheal intubation and IPPV have for many years been the standard methods of resuscitating severely asphyxiated newborn infants. The aim is to expand and ventilate the lungs and to stimulate the infant into spontaneous respiration. Few attempts have been made to evaluate this technique or to study its effects on the neonate. Cross et al. (1960) showed that lung inflation in the neonatal period often produces reflex inspiratory efforts-such as, Head's paradoxical reflex. However, Hull (1969) demonstrated that during resuscitation the most common initial response to lung inflation is a reflex expiratory effort.

Pressure and volume studies on isolated newborn lung preparations have demonstrated an 'opening pressure' which has to be exceeded in order to expand the lung (Agostini, 1959; Gribetz et al., 1959; Craig, 1963; Gruenwald, 1963; Rosen and Laurence, 1965). However, Karlberg showed that some spontaneously breathing babies are able to expand their lungs with a small opening pressure (Karlberg and Koch, 1962, Karlberg et al. 1962). More recently, Milner and Saunders (1977) showed that this is the most common pattern of lung expansion at birth. We therefore wanted to study the response of the newborn infant to resuscitation and to find out if an opening pressure was exhibited in the lungs of babies requiring resuscitation.

\section{Method}

Apparatus. The apparatus used was a Vickers

Department of Neonatal Medicine and Surgery,

Nottingham City Hospital

A. W. BOON, research fellow

I. E. HOPKIN, research sister

Department of Child Health, Nottingham

A. D. MILNER, reader in child health resuscitation trolley with a spring-loaded valve set at $30 \mathrm{cmH}_{2} \mathrm{O}(2.94 \mathrm{kPa})$ in the inspiratory line. Oxygen was delivered at a rate of $3 \mathrm{l} / \mathrm{min}(0.05$ 1/second) via a modified T-piece (Fig. 1). Inflation pressure was measured using a strain gauge pressure transducer (SE Labs SEM 4-86). Intrathoracic pressure changes were measured using an 8 FG water-filled catheter perfused at a rate of $1 \mathrm{ml} /$ hour using an infusion pump (Sandoz infusion pump). Tidal flow was measured across a pneumotachograph using an Elema-Schönander differential pressure transducer (EMT 32C). The flow signal was fed through an electronic integrator to produce the tidal volume. The oesophageal and inflation

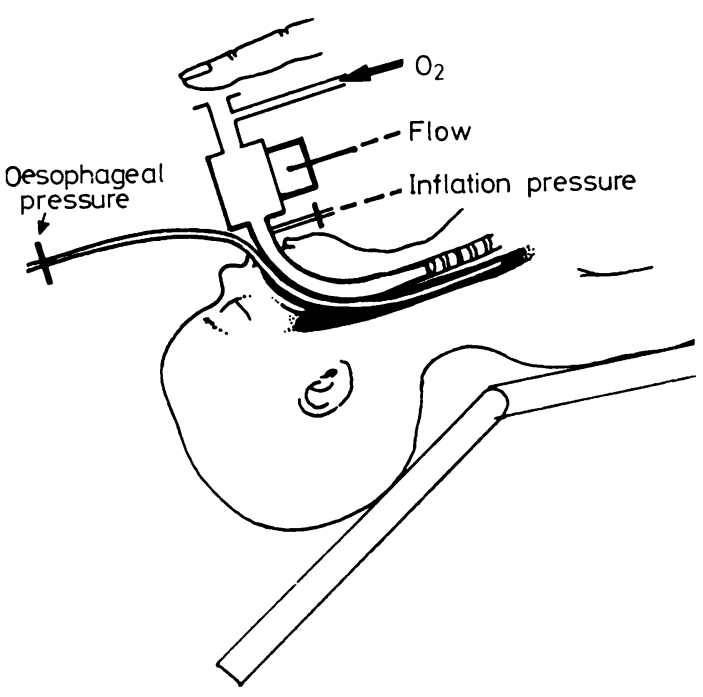

Fig. 1 Diagrammatic representation of modified T-piece. 
pressures were calibrated against a water-filled manometer at the end of each run. The flow was calibrated using a rotameter and the tidal volume by injecting a known volume of air through the T-piece. The signals were transferred via an amplification system (SE Emma) to a 4-channel FM tape recorder (SE 84) and simultaneously displayed on a multichannel oscilloscope (SE Labs SEM 430).

Technique. The baby was placed on the resuscitation trolley immediately after delivery. Standard indications for resucitation were used-that is, the infant was apnoeic with a falling heart rate, hypotonic with no response to oropharyngeal suction, and a blue or white colour (Apgar score 3 or less).

A Warne's 14 FG neonatal tube was used routinely. The oesophageal catheter was passed orally while withdrawing the laryngoscope. The tube was passed to a distance of $13 \mathrm{~cm}$ from the lips so that the end lay in the lower third of the oesophagus (Milner $e t$ al., 1978a). The baby's lungs were inflated at a rate of $30-40 / \mathrm{min}$ using an inflation time of approximately 1 second.

Data analysis. The data were analysed in two ways. The output from the tape recorder was fed into a 6-channel recorder with ultraviolet-sensitive paper (SE Oscillograph Se 3006). The inflation pressure and tidal volume signals were also played through an X-Y plotter (SE 225 Mark II) at $25 \%$ of the recording speed in order to construct pressurevolume loops of each lung inflation.
The frequency response of the system was assessed by mounting the oesophageal catheter and T-piece with endotracheal tube in a bung which was sealed in a 3-litre container. The open end of the T-piece was occluded and one of the tubes from the pneumotachograph was clamped off. The response characteristics were first determined by injecting $20 \mathrm{ml}$ air rapidly via the $T$-piece into the container. The response times of the volume and inflation pressure signals were identical. As the limiting factor was the rate of injection of air, a sudden rise in pressure was achieved by bursting an inflated rubber balloon within the container. The $63 \%$ rise time of the pneumotachograph and inflation pressure systems were identical at $6 \cdot 2$ milliseconds giving a damping of $3 \mathrm{~dB} /$ octave at $25 \cdot 7 \mathrm{~Hz}$. The $63 \%$ rise time of the oesophageal pressure system was 13.2 milliseconds producing a $3 \mathrm{~dB} /$ octave attentuation at $11 \cdot 7 \mathrm{~Hz}$.

Subjects. Recordings were made in a total of 20 asphyxiated neonates born by lower segment caesarean section at a mean birthweight of $3.06 \mathrm{~kg}$ and gestation of 39 weeks. The Table gives the clinical details of the infants; 15 of them were delivered by elective caesarean section and 5 by emergency caesarean section. After preoxygenation, general anaesthesia was induced with thiopentone and suxamethonium. Anaesthesia was maintained with nitrous oxide and oxygen, with the addition of halothane in 9 cases, atropine in 4 , and pancuronium in 4. Twelve of the babies had gasped or cried before becoming apnoeic.

Table Clinical details of 20 babies

\begin{tabular}{|c|c|c|c|c|c|c|c|c|c|}
\hline \multirow[t]{2}{*}{ Case } & \multirow{2}{*}{$\begin{array}{l}\text { Birthweight } \\
(\mathrm{kg})\end{array}$} & \multirow{2}{*}{$\begin{array}{l}\text { Gestation } \\
\text { (weeks) }\end{array}$} & \multirow{2}{*}{$\begin{array}{l}\text { Indication } \\
\text { for LSCS }\end{array}$} & \multirow{2}{*}{$\begin{array}{l}\text { Time from } \\
\text { general anaesthesia } \\
\text { to delivery (min) }\end{array}$} & \multirow{2}{*}{$\begin{array}{l}\text { No. of gasps } \\
\text { before } \\
\text { intubation }\end{array}$} & \multirow{2}{*}{$\begin{array}{l}\text { Time from } \\
\text { intubation } \\
\text { to regular } \\
\text { respiration } \\
\text { (min) }\end{array}$} & \multicolumn{3}{|c|}{ Response to inflation } \\
\hline & & & & & & & Ist & $2 n d$ & $3 r d$ \\
\hline $\begin{array}{l}1 \\
2 \\
3\end{array}$ & $\begin{array}{l}3 \cdot 590 \\
4 \cdot 150 \\
2 \cdot 000\end{array}$ & $\begin{array}{l}40 \\
40 \\
40\end{array}$ & $\begin{array}{l}\text { Transverse lie } \\
\text { Breech } \\
\text { Failing placental } \\
\quad \text { function }\end{array}$ & $\begin{array}{l}25 \\
15 \\
10\end{array}$ & $\begin{array}{l}\mathbf{0} \\
\mathbf{3} \\
\mathbf{0}\end{array}$ & $\begin{array}{l}4 \\
2 \\
2 \frac{1}{2}\end{array}$ & $\begin{array}{l}\text { None } \\
\mathbf{R} \\
\mathbf{R} / \mathbf{H}\end{array}$ & $\begin{array}{l}\text { None } \\
\mathbf{R} \\
\text { None }\end{array}$ & $\begin{array}{l}\mathbf{R} \\
\mathbf{R} \\
\text { None }\end{array}$ \\
\hline $\begin{array}{r}4 \\
5 \\
6 \\
7 \\
8 \\
9 \\
10 \\
11 \\
12 \\
13 \\
14 \\
15 \\
16^{*} \\
17^{*} \\
18^{*} \\
19^{*} \\
20^{*}\end{array}$ & $\begin{array}{l}3 \cdot 128 \\
2 \cdot 980 \\
3 \cdot 400 \\
2 \cdot 740 \\
2 \cdot 940 \\
2 \cdot 330 \\
2 \cdot 940 \\
1 \cdot 200 \\
3 \cdot 400 \\
2 \cdot 910 \\
3 \cdot 990 \\
3 \cdot 850 \\
3 \cdot 050 \\
2 \cdot 800 \\
3 \cdot 570 \\
2 \cdot 720 \\
3 \cdot 460\end{array}$ & $\begin{array}{l}40 \\
40 \\
37 \\
37 \\
40 \\
40 \\
40 \\
31 \\
39 \\
40 \\
42 \\
39 \\
40 \\
39 \\
40 \\
36 \\
40\end{array}$ & $\begin{array}{l}\text { Disproportion } \\
\text { Breech } \\
\text { Diabetic } \\
\text { Breech } \\
\text { Breech } \\
\text { Breech } \\
\text { Breech } \\
\text { Hypertension } \\
\text { Transverse lie } \\
\text { Breech } \\
\text { Pre-eclampsia } \\
\text { Breech } \\
\text { Breech } \\
\text { Disproportion } \\
\text { Brow presentation } \\
\text { Fetal distress } \\
\text { Fetal distress }\end{array}$ & $\begin{array}{l}13 \\
7 \cdot 5 \\
8 \\
12 \\
10 \\
8 \\
13 \\
8 \cdot 5 \\
11 \\
10 \cdot 5 \\
8 \\
9 \\
12 \\
13 \\
12 \\
4 \cdot 5 \\
7\end{array}$ & $\begin{array}{l}\text { Cry } \\
1 \\
0 \\
2 \\
0 \\
3 \\
1 \\
1 \\
1 \\
1 \\
0 \\
2+\text { cry } \\
\text { Cry } \\
0 \\
0 \\
1 \\
1+\text { cry }\end{array}$ & $\begin{array}{l}4 \\
5 \\
3 \\
2 \\
4 \\
3 \\
4 \\
2 \frac{1}{2} \\
2 \\
1 \frac{1}{2} \\
3 \\
3 \frac{1}{2} \\
2 \\
7 \\
3 \\
3 \\
3\end{array}$ & $\begin{array}{l}\text { None } \\
\mathbf{R} \\
\mathbf{R} / \mathbf{H} \\
\mathbf{H} \\
\mathbf{R} \\
\mathbf{R} \\
\mathbf{N} o n e \\
\mathbf{H} \\
\mathbf{R} \\
\mathbf{N} o n e \\
\mathbf{R} \\
\mathbf{R} \\
\mathbf{R} \\
\mathbf{R} \\
\mathbf{R} \\
\mathbf{R} \\
\mathbf{R}\end{array}$ & $\begin{array}{l}\text { None } \\
\mathbf{R} \\
\mathbf{R} / \mathbf{H} \\
\text { None } \\
\text { None } \\
\mathbf{R} \\
\text { None } \\
\mathbf{R} \\
\mathbf{R} / \mathbf{H} \\
\text { None } \\
\mathbf{R} / \mathbf{H} \\
\mathbf{R} \\
\mathbf{R} / \mathbf{H} \\
\mathbf{R} / \mathbf{H} \\
\text { None } \\
\mathbf{R} \\
\mathbf{R}\end{array}$ & $\begin{array}{l}\text { None } \\
\mathbf{R} / \mathbf{H} \\
\mathbf{R} / \mathbf{H} \\
\text { None } \\
\mathbf{R} / \mathbf{H} \\
\mathbf{R} \\
\text { None } \\
\text { None } \\
\mathbf{H} \\
\mathbf{H} \\
\text { None } \\
\mathbf{R} \\
\mathbf{R} / \mathbf{H} \\
\mathbf{R} \\
\mathbf{R} \\
\mathbf{R} \\
\text { None }\end{array}$ \\
\hline
\end{tabular}

*Emergency segment caesarean section, $\mathbf{L S C S}=$ lower segment caesarean section, $\mathbf{R}=$ rejection response, $H=H e a d$ 's paradoxical reflex. 
These subjects were matched for birthweight and gestation with 23 babies born by lower segment caesarean section who did not require resuscitation at birth. The project was passed by the North Nottingham ethical committee.

\section{Results}

Responses to lung inflation. The responses of the baby to the first 3 inflations were analysed. In some instances more than one response was seen, therefor the responses add up to more than 60 .

\section{Rejection response}

The most common response to lung inflation was a large positive intraoesophageal pressure-that is expiratory effort of up to $11 \mathrm{kPa}$ (Figs 2 and 3). This response was seen with 37 inflations. The positive pressure ranged from 13-114 $\mathrm{cmH}_{2} \mathrm{O}$ $(1 \cdot 27-11 \cdot 18 \mathrm{kPa})$ with a mean of $63.9 \mathrm{cmH}_{2} \mathrm{O}$ $(6 \cdot 26 \mathrm{kPa})$. This response by the baby frequently caused expulsion of gas from the lungs while the inflation pressure was maintained (Fig. 3).

\section{Head's paradoxical reflex}

On 15 occasions the infant responded to lung inflation with an inspiratory effort (negative oesophageal pressure)-that is, Head's paradoxical reflex (Figs 4 and 5). The negative pressure produced ranged from $3 \cdot 6-48 \mathrm{cmH}_{2} \mathrm{O}(0 \cdot 35-4 \cdot 70 \mathrm{kPa})$ with a mean of $20.1 \mathrm{cmH}_{2} \mathrm{O}(1.97 \mathrm{kPa})$. These inspiratory efforts often produced a fall in inflation

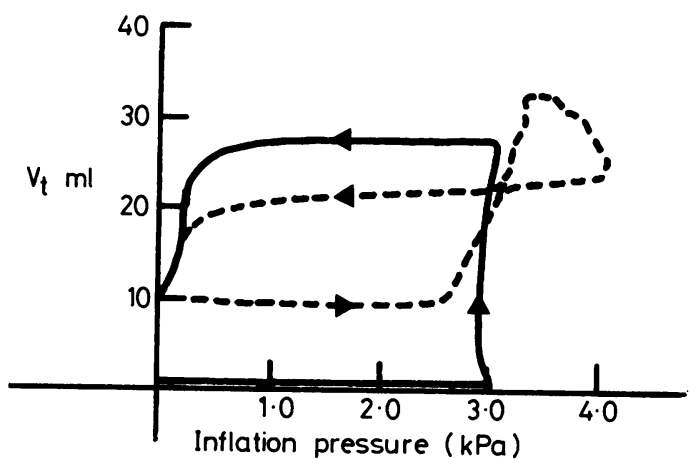

Fig. 3 (Case 9). $X-Y$ plot of inflation pressure against volume. In this and in subsequent $X-Y$ plots, the 1 st breath is represented by a solid line and the 2nd by a dashed line. During the 2nd inflation, gas was expelled from the lungs by the baby's 'rejection response'.

pressure, sometimes resulting in negative endotracheal pressures of up to $30 \mathrm{cmH}_{2} \mathrm{O}(2.94 \mathrm{kPa})$ despite a biased flow of $3 \mathrm{l} / \mathrm{min}$.

\section{Passive inflation}

On 17 occasions the baby's lungs were inflated with no active change in the oesophageal pressure. The pressure change in these instances was merely being transmitted across the lung (Figs 6 and 7).

On two occasions there was no oesophageal pressure change and no oxygen entered the lungs (Fig. 8).



Fig. 2 (Case 9). Inflation pressure, oesophageal pressure, and tidal volume $\left(V_{t}\right)$ plotted against time, showing a 'rejection response' to lung inflation. Preinflation oesophageal pressure has been arbitrarily chosen as zero. The baby formed a functional residual capacity $(F R C)$ of $10 \mathrm{ml}$. 




Fig. 4 (Case 14).

'Longitudinal trace' showing a rejection response to the 1st inflation with a Head's paradoxical reflex and rejection response to the 2nd inflation. Note the pronounced swings in inflation pressure.

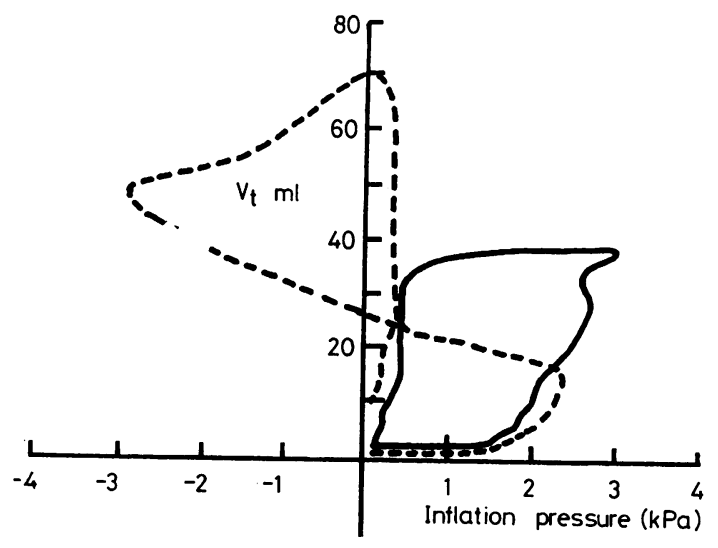

Fig. 5 (Case 6). $X-Y$ plot of inflation pressure against volume. The 2nd inflation was associated with a Head's paradoxical reflex and a pronounced increase in the volume of gas entering the lung. Note the low opening pressure of $1.5 \mathrm{kPa}$ unlike that in Fig. 3.
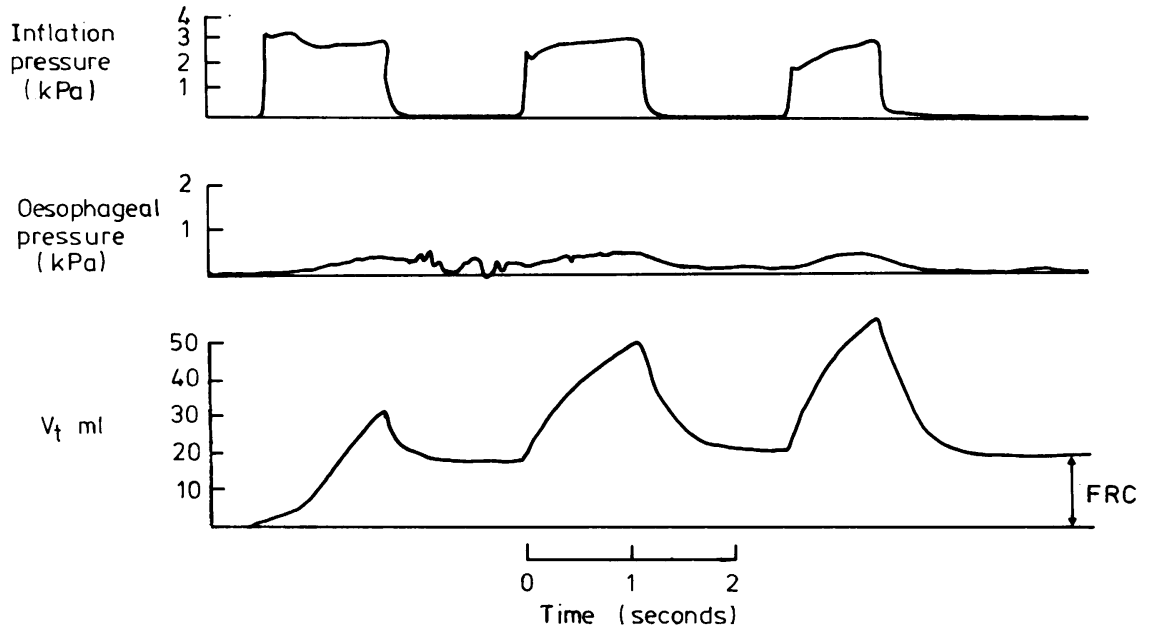

Fig. 6 (Case 10). 'Longitudinal trace' showing small passively transmitted changes in oesophageal pressure with each inflation. 


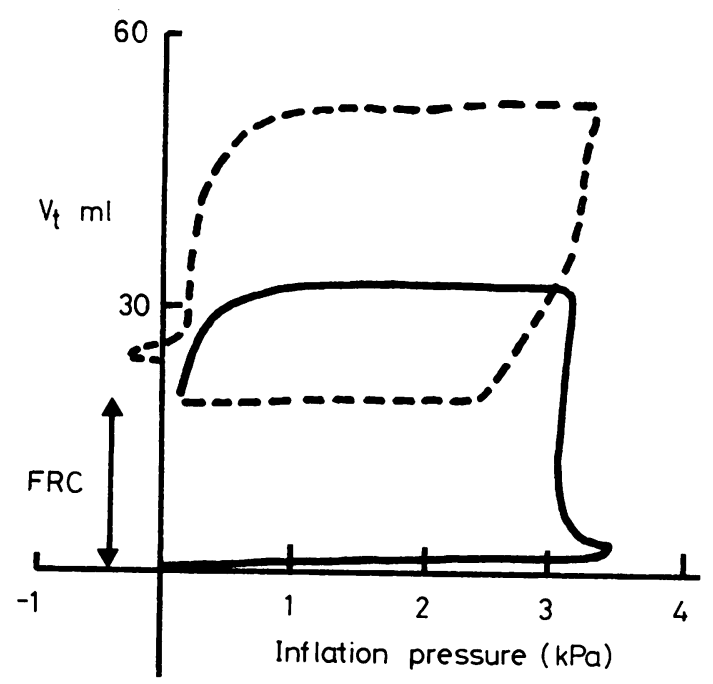

Fig. 7 (Case 10). $X-Y$ plot of the same baby as in Fig. 5. Again, there was an opening pressure in excess of $3 \mathrm{kPa}$.

Inflation pressures and volumes during resuscitation. It was only possible to construct pressure/volume loops in 12 of the 20 babies. In the other 8 babies, the initial volume trace was unsatisfactory because of integrator drift and had to be obtained by integrating tidal flow from the tape recordings. Of the 12 babies on whom full data were available, 10 required an opening pressure of $2.0 \mathrm{kPa}$ or more (mean $2.69 \mathrm{kPa}$ ) in order to expand their lungs (Figs 3 and 7). Rather surprisingly, 7 of this group had gasped before becoming apnoeic. In 2 infants lung expansion started with a pressure of 1.5 in one and $1.3 \mathrm{kPa}$ in the other (Fig. 5).

Factors affecting the response to lung inflation. The intubated group of babies was compared with 23 matched controls who had a mean birthweight of $3.24 \mathrm{~kg}$ and gestation of 39.7 weeks. There was no significant difference in the indication for caesarean section or anaesthetic agents given to the mothers. However, the time from induction of anaesthesia to delivery of the baby was significantly shorter in the control group than in the intubated group (7.82 compared with $10 \cdot 85$ minutes, $P<0 \cdot 02$ ). Furthermore, the longer the interval between induction of anaesthesia and delivery of the baby, the fewer the active responses to lung inflation produced by the baby. However, whether the baby had gasped or cried before becoming apnoeic did not predict the baby's response.

\section{Discussion}

This study confirms the work of Hull (1969) that the most common initial response to lung inflation is a reflex expiratory effort. It is possible that this large positive intrathoracic pressure represents a cough or a cry, although this is somewhat unexpected in an infant who has previously made little or no response to mucosal stimulation or tracheal intubation. It is obviously impossible to identify, without complicated electromyography, whether this is a cough or cry when the baby is intubated. Only three groups of lung mechanoreceptor are known to be stimulated by lung inflation: (1) pulmonary stretch



Fig. 8 (Case 8). Longitudinal trace of a baby who showed all four types of responses to the first 3 inflations. 
receptors, which inhibit respiratory activity; (2) nonmyelinated vagal fibres responding to chemicals and large lung inflations to cause apnoea and rapid shallow breathing; (3) lung irritant receptors which normally cause a gasp (Coleridge et al., 1965; Mills et al., 1970; Sellick and Widdicombe, 1970). However, direct stimulation of the irritant receptors in newborn infants frequently causes apnoea or slowing of respiration (Fleming et al., 1978). It is of interest that reinflation of a collapsed lung in healthy adults sometimes causes a cough (Burger and Macklem, 1968). It seems possible that this response is mediated via pulmonary irritant receptors.

Whatever the mechanism of the response, it was seen less often in the more severely asphyxiated babies and in those infants in whom there had been a particularly long interval between the induction of anaesthesia and delivery of the infant. It is interesting that spontaneously breathing babies who were not intubated also commonly produce large intrathoracic pressures on their first expiration (Karlberg et al., 1962; Milner and Saunders, 1977). It is therefore unlikely that this effect is merely caused by the stimulus of cold gas on the respiratory epithelium.

Like Hull (1969) we have shown that Head's paradoxical reflex is seen less often in the initial lung inflation during resuscitation. It was of interest that the baby's own inspiratory efforts were often much more efficient in causing lung expansion than the inflating pressure (Fig. 4). It is not possible to say whether these responses are those of the normal asphyxiated neonate or whether there has been a modification of the response caused by the anaesthetic agent used.

Despite using what is normally accepted as an adequate flow rate of oxygen of $0.051 /$ second (3 $\mathrm{l} / \mathrm{min}$ ) (Hull, 1969; Robinson, 1977), the baby's own inspiratory efforts frequently produced large fluctuations in the inflation pressure. It is possible that these large and rapid pressure swings may predispose the infant to develop a pneumothorax and for this reason it may be that higher flow rates of oxygen should be used to lessen this possibility.

It appears from these data that, unlike spontaneously breathing infants, babies requiring resuscitation at birth exhibit an opening pressure remarkably similar to $20 \mathrm{cmH}_{2} \mathrm{O}(1.96 \mathrm{kPa})$ calculated on theoretical grounds by Avery and Mead (1959) and found by workers inflating isolated lungs (Agostini, 1959; Gribetz et al., 1959; Craig, 1963; Gruenwald, 1963; Rosen and Laurence, 1965). It is unlikely that the opening pressures we demonstrated are artefactual, as the frequency response of the inflation pressure and pneumotachograph systems was identical.

One possible reason for this opening pressure difference between spontaneously breathing and resuscitated babies may be that the baby's own efforts are more efficient at expanding the lungs as the force is being applied from all around the lungs.

Another factor which may account for the higher opening pressures in resuscitated babies may be that they were all born by lower segment caesarean section and therefore had not benefited from the effects of vaginal delivery in expressing liquid from the lungs (Milner et al., 1978b) or from any other changes as the baby passes down the birth canal. It is unlikely that the pressure differences are due to the presence or absence of surfactant as none of the resuscitated babies developed any respiratory distress.

To try to clarify this difference we now intend to study vaginally-born babies requiring resuscitation at birth.

\section{Conclusion}

We feel it is important to state that there is still no way of predicting clinically which apnoeic babies are severely asphyxiated and whether they will produce active responses to resuscitation. Furthermore, babies who had cried or gasped at birth did not appear to differ from the group as a whole and sometimes produced no responses (for example, Cases 4 and 10). Intubation and IPPV should therefore continue to be the standard method of resuscitating apnoeic neonates.

We are grateful to Professor D. Hull for advice, and to the obstetric and theatre staff of the maternity unit at the City Hospital for help. This study was supported by an MRC grant.

\section{References}

Agostini, E. (1959). Volume-pressure relationships of the thorax and the lung in the newborn. Journal of Applied Physiology, 14, 909-913.

Avery, M. E., and Mead, J. (1959). Surface properties in relation to atelectasis and hyaline membrane disease. American Journal of Diseases of Children, 97, 517-523.

Burger, E. J., and Macklem, P. (1968). Airway closure: demonstration by breathing $100 \% \mathrm{O}_{2}$ at low lung volumes and by $\mathrm{N}_{2}$ washout. Journal of Applied Physiology, 25, 139-148.

Coleridge, H. M., Coleridge, J. C. G., and Luck, J. C. (1965). Pulmonary afferent fibres of small diameter stimulated by capsaicin and by hyperinflation of the lungs. Journal of Physiology, 179, 248-262.

Craig, J. M. (1963). Distensibility curves and expansion patterns of newborn lungs. American Journal of Diseases of Children, 106, 174-184.

Cross, K. W., Klaus, M., Tooley, W. H., and Weisser, K. (1960). The response of the newborn baby to inflation of the lungs. Journal of Physiology, 151, 551-565. 
Fleming, P. J., Bryan, A. C., and Bryan, M. H. (1978). Functional immaturity of pulmonary irritant receptors and apnea in newborn preterm infants. Pediatrics, 61, 515-518.

Gribetz, I., Frank, N. R., and Avery, M. E. (1959). Static volume-pressure relations of excised lungs of infants with hyaline membrane disease, newborn and stillborn infants. Journal of Clinical Investigation, 38, 2168-2175.

Gruenwald, P. (1963). Respiratory studies in newborn infants II. Normal and abnormal expansion of the lungs of newborn infants obtained at autopsy. Opening pressure, maximal volume, and stability of expansion. Laboratory Investigation, 12, 563-576.

Hull, D. (1969). Lung expansion and ventilation during resuscitation of asphyxiated newborn infants. Journal of Pediatrics, 75, 47-58.

Karlberg, P., and Koch, G. (1962). Respiratory studies in newborn infants. III. Development of mechanics of breathing during the first week of life. A longitudinal study. Acta paediatrica, 135, Supplement, 121-129.

Karlberg, P., Cherry, R. B., Escardo, F. E., and Koch, G. (1962). Pulmonary ventilation and mechanics of breathing in the first minutes of life, including the onset of respiration. Acta paediatrica Scandinavica, 51, 121-136.

Mills, J. E., Sellick, H., and Widdicombe, J. G. (1970). Epithelial irritant receptors in the lungs. In Breathing: Hering-Breuer Centenary Symposium, pp. 77-92. Edited by R. Porter. Churchill: London.
Milner, A. D., and Saunders, R. A. (1977). Pressure and volume changes during the first breath of human neonates. Archives of Disease in Childhood, 52, 918-924.

Milner, A. D., Saunders, R. A., and Hopkin, I. E. (1978a). Tidal pressure/volume and flow/volume respiratory loop patterns in human neonates. Clinical Science and Molecular Medicine, 54, 257-264.

Milner, A. D., Saunders, R. A., and Hopkin, I. E. (1978b). Effects of delivery by caesarean section on lung mechanics and lung volume in the human neonate. Archives of Disease in Childhood, 53, 545-548.

Robinson, R. (1977). Resuscitation of the newborn. British Journal of Hospital Medicine, 17, 260-271.

Rosen, M., and Laurence, K. M. (1965). Expansion pressure and rupture pressures in the newborn lung. Lancet, 2, 721-722.

Sellick, H., and Widdicombe, J. G. (1970). Vagal deflation and inflation reflexes mediated by lung irritant receptors. Quarterly Journal of Experimental Physiology, 55, 153-163.

Correspondence to Dr A. D. Milner, Department of Child Health, Queen's Medical Centre, Clifton Boulevard, Nottingham NG7 2UH.

Received 31 October 1978 